\title{
Efficacy of Bimatoprost Plus Timolol Fixed Combination in Open Angle Glaucoma Patients Previously Treated with Dorzolamide Plus Timolol Fixed Combination
}

\author{
Matteo Sacchi, Claudia Specchia, Susan E. Williams, Edoardo Villani \& Paolo \\ Nucci
}

To cite this article: Matteo Sacchi, Claudia Specchia, Susan E. Williams, Edoardo Villani \& Paolo Nucci (2016): Efficacy of Bimatoprost Plus Timolol Fixed Combination in Open Angle Glaucoma Patients Previously Treated with Dorzolamide Plus Timolol Fixed Combination, Current Eye Research, DOI: 10.3109/02713683.2015.1125507

To link to this article: http://dx.doi.org/10.3109/02713683.2015.1125507

Published online: 26 Apr 2016.

Submit your article to this journal $₫$

Џ Article views: 41

View related articles

View Crossmark data $₫$ 


\title{
Efficacy of Bimatoprost Plus Timolol Fixed Combination in Open Angle Glaucoma Patients Previously Treated with Dorzolamide Plus Timolol Fixed Combination
}

\author{
Matteo Sacchia, Claudia Specchiaa ${ }^{\mathrm{b}, \mathrm{c}}$, Susan E. Williams ${ }^{\mathrm{d}}{ }^{\mathrm{d}}$, Edoardo Villania ${ }^{\mathrm{a}}$, and Paolo Nucci $\mathbb{1}^{\mathrm{a}}$ \\ aUniversity Eye Clinic, San Giuseppe Hospital, University of Milan, Milan, Italy; ${ }^{b}$ Department of Molecular and Translational Medicine, University of \\ Brescia, Brescia, Italy; 'IRCCS MultiMedica, Milan, Italy; 'Division of Ophthalmology, Department of Neurosciences, University of the Witwatersrand, \\ Johannesburg, South Africa
}

\begin{abstract}
Purpose: To evaluate the efficacy and safety of bimatoprost plus timolol fixed combination (BTFC) in patients with primary open angle glaucoma (POAG) previously treated with dorzolamide plus timolol fixed combination (DTFC).

Materials and methods: Retrospective, medical records review study. Medical records of patients with POAG previously treated with DTFC and then switched to BTFC for poor intraocular pressure (IOP) control or ocular discomfort were included in the analysis. One baseline IOP diurnal curve, and one diurnal curve under each treatment were required to be eligible for this study. The primary outcome was to compare the mean diurnal IOP between DTFC and BTFC. Secondary outcomes were to compare the IOP diurnal fluctuation, and the percentage of patients achieving a target IOP $<14,<16$, and $<18 \mathrm{mmHg}$ between the two treatments.

Results: Medical records of 96 patients were analyzed (mean age 65.8 years \pm 7.2 , range 39-89 years). The mean diurnal IOP was $23.7 \pm 3.8 \mathrm{mmHg}$ at baseline, $16.9 \pm 3.4 \mathrm{mmHg}$ with DTFC and $15.1 \pm 2.9 \mathrm{mmHg}$ after therapy was switched to BTFC ( $p<0.0001$ each treatment vs baseline; $p<0.0001$ DTFC vs BTFC). The proportion of patients achieving a mean diurnal IOP $<18,<16$, and $<14 \mathrm{mmHg}$ was $76 \%, 35.4 \%$, and $12.5 \%$ with DTFC and $81.2 \%, 68.8 \%$, and $37.5 \%$ with BTFC $(p=0.20, p<0.01$, and $p<0.0001$ between the two treatments, respectively). IOP fluctuation did not differ significantly between the treatments.

Conclusion: BTFC can provide additional lowering in the mean diurnal IOP in patients previously treated with DTFC with no significant differences in the safety and tolerability profile.
\end{abstract}

\section{ARTICLE HISTORY}

Received 4 September 2015 Revised 3 November 2015

Accepted 25 November 2015

\section{KEYWORDS}

Bimatoprost plus timolol fixed combination; dorzolamide plus timolol fixed combination; intraocular pressure; intraocular pressure fluctuations; open angle glaucoma
Intraocular pressure (IOP) lowering therapy is, currently, the only accepted, evidence-based approach for the treatment of glaucoma. Large, controlled, multicenter randomized studies have demonstrated that reducing IOP can prevent glaucoma onset from ocular hypertension ${ }^{1}$ and glaucoma progression in patients with a confirmed diagnosis of glaucoma. ${ }^{2-4}$ In normal tension glaucoma, a randomized clinical trial concluded that an IOP lowering approach can reduce the risk of disease progression. ${ }^{5}$ According to the European Glaucoma Society Guidelines, ${ }^{6}$ IOP lowering treatment with monotherapy should be the first approach. Combination therapy is the second-line treatment option when an additional IOP lowering agent is needed for adequate IOP control. This is in preference to the addition of a second medication to the first that carries the risk of lower patient compliance with an increase in the complexity of the dosage regimen. A fixed combination (FC) of two drugs in a single product offers the advantage of a simplified dosage regimen. It has been shown that adherence to the treatment as well as patient quality of life are higher with once-daily FC therapy compared to the use of unfixed combinations of different drugs. A reduced risk of washout of the first administered medication and a decreased exposure to preservative are other advantages of FC. ${ }^{7-9}$
Prostaglandin analogs plus timolol FC and carbonic anhydrase inhibitor plus timolol FC are among the most commonly prescribed FCs in patients with glaucoma, however only one report is available comparing these two classes of IOP lowering agents. ${ }^{10}$ The aim of this retrospective study is to compare the efficacy of bimatoprost plus timolol fixed combination (BTFC) and dorzolamide plus timolol fixed combination (DTFC) in patients with primary open angle glaucoma.

\section{Materials and methods}

A retrospective, single center chart review of patients referred to Eye Clinic San Giuseppe Hospital (Milan, Italy) from January 2011 to January 2014 was conducted. For this study the electronic hospital database was screened for "primary open angle glaucoma" and then patients switched to BTFC from the previous treatment with DTFC were identified. The study and data accumulation were carried out with approval from the Institutional Ethics Committee (San Giuseppe Hospital, MultiMedica) and adhered to the tenets of the Declaration of Helsinki.

CONTACT Matteo Sacchi matteosacchi.hsg@gmail.com University Eye Clinic, San Giuseppe Hospital, University of Milan, Via San Vittore 12, 20123, Milano, Italy. 
Inclusion criteria were the charts of patients older than 18 years with a diagnosis of primary open-angle glaucoma according to the European Glaucoma Society Guidelines criteria; ${ }^{6}$ best-corrected visual acuity $\geq 20 / 100$ (Snellen acuity) in each eye; treatment with DTFC (Cosopt, Merck, Whitehouse Station, NJ) twice-daily for at least 3 months, and with BTFC (Ganfort, Allergan, Irvine, California) once in the evening for at least 3 months after the switch from DTFC.

Exclusion criteria were a diagnosis of ocular hypertension, angle closure or secondary glaucoma; ocular surgery or laser trabeculoplasty 3 months before or during the treatment period; ocular disease affecting IOP (for example uveitis); the use of topical ocular medication with effects on IOP and patients with a history of refractive surgery.

\section{Study design}

Every patient referred to the Glaucoma Unit of the Eye Clinic San Giuseppe Hospital (Milan, Italy) receives a complete ophthalmic examination together with a diurnal IOP curve (with IOP measured at $8.00,11.00,14.00$, and 17.00). IOP measurements are performed by trained physician with calibrated Goldmann applanation tonometers and adverse events related to medications are recorded in the charts. For the patient charts to be included in the review, the following diurnal IOP curves had to be available for analysis: one curve at baseline (before any treatment), one curve with DTFC, and one curve with BTFC. Only one eye per patient (the eye with the higher baseline IOP or the right eye in case of equal baseline IOPs) was selected for analysis. The patients that were included in the study had been switched from DTFC to BTFC either for inadequate IOP control (as judged by the physician) or for ocular discomfort. Because there was no washout period, we only analyzed the BTFC IOP curves performed more than 12 weeks after the switch from previous treatment with DTFC in order to minimize the impact of the previous therapy.

Mean diurnal IOP was calculated as the mean of the four IOP diurnal measurements from the daily curve. The mean value of 2 measurements at each time point (or the median of 3 readings if the first 2 differed by more than $2 \mathrm{~mm} \mathrm{Hg}$ ) was used in the calculations. The IOP fluctuation was calculated as the difference between the highest and the lowest IOP readings within the diurnal curve for each patient.

\section{Outcome}

The primary outcome was to compare the mean diurnal IOP obtained with DTFC with the mean diurnal IOP after switch to BTFC.

The secondary outcomes were to compare the diurnal IOP fluctuation and the proportion of patients achieving a mean diurnal IOP of less than $18 \mathrm{mmHg}$, less than $16 \mathrm{mmHg}$ and less than $14 \mathrm{mmHg}$ between the two treatments. Adverse events and side effects related to treatment were evaluated as previously described. ${ }^{11}$

\section{Statistical analysis}

The difference in the mean intraocular pressure (IOP) between treatments was evaluated using the paired $t$-test. The null hypothesis of equal variations of mean diurnal IOP among strata was evaluated using analysis of variance.

To correct for multiple comparisons at individual time points, a Bonferroni adjustment was used. The proportion of patients with a mean diurnal IOP less than 18, 16, and $14 \mathrm{mmHg}$ in each of the two treatment groups was compared using Mc-Nemar's test. All reported $p$-values are two-sided. A $p$-value $<0.05$ was considered statistically significant. All analyses were performed using $R$ (www.r-project.org).

The study had a $90 \%$ power to identify a $1.0 \mathrm{~mm} \mathrm{Hg}$ difference in the mean diurnal IOP values and at the individual time points assuming a standard deviation of $2.5 \mathrm{~mm} \mathrm{Hg}$ if at least 90 patients were enrolled (two tailed paired $t$-test, $a=0.01$ ).

\section{Results}

\section{Baseline demographics and patient characteristics}

Among the patients referred to Eye Clinic San Giuseppe Hospital from January 2011 to January 2014, 96 Caucasian patients met the inclusion criteria and were included in the analysis. The mean age of the patients was 65.8 years (SD 7.2, range 39-89 years). Baseline patient characteristics (referring to patients before they were put on DTFC) have been reported in Table 1.

\section{Efficacy}

The mean diurnal IOP from the daily curve was $23.7 \pm$ $3.8 \mathrm{mmHg}$ (baseline), $16.9 \pm 3.4 \mathrm{mmHg}$ (with DTFC), and $15.1 \pm 2.9 \mathrm{mmHg}$ after therapy was switched to BTFC (Figure 1, Table 2).

Both medications reduced mean IOP significantly when compared with untreated baseline $(p<0.0001)$. When the two medications were compared directly, BTFC showed a greater IOP lowering efficacy than DTFC $(p<0.0001)$. Variations of mean diurnal IOP were similar by age, sex and previous treatments.

Table 1. Baseline patient characteristics $(n=96)$.

\begin{tabular}{lc}
\hline Age, years (mean \pm SD) & $65.8 \pm 7.2$ \\
Sex, $n(\%)$ & \\
Male & $50(52.1 \%)$ \\
Female & $46(47.9 \%)$ \\
CCT, $\mu$ icron (mean \pm SD) & $549 \pm 23.2$ \\
MD, dB (mean \pm SD) & $-6.36 \pm 2.4$ \\
Pseudophakia & $36(37.5 \%)$ \\
Previous treatment, $n(\%)$ & \\
Naïve & $25(26 \%)$ \\
PGAs & $24(25 \%)$ \\
BB & $17(17.7 \%)$ \\
CAl-timolol FC & $10(10.4 \%)$ \\
Brimonidinetimolol FC & $9(9.4 \%)$ \\
Brimonidine & $7(7.3 \%)$ \\
CAI & $4(4.2 \%)$ \\
\hline
\end{tabular}

PGAs = prostaglandin analogs.

$\mathrm{BB}=$ beta blockers.

$\mathrm{CAI}=$ carbonic anidrase inhibitor. 


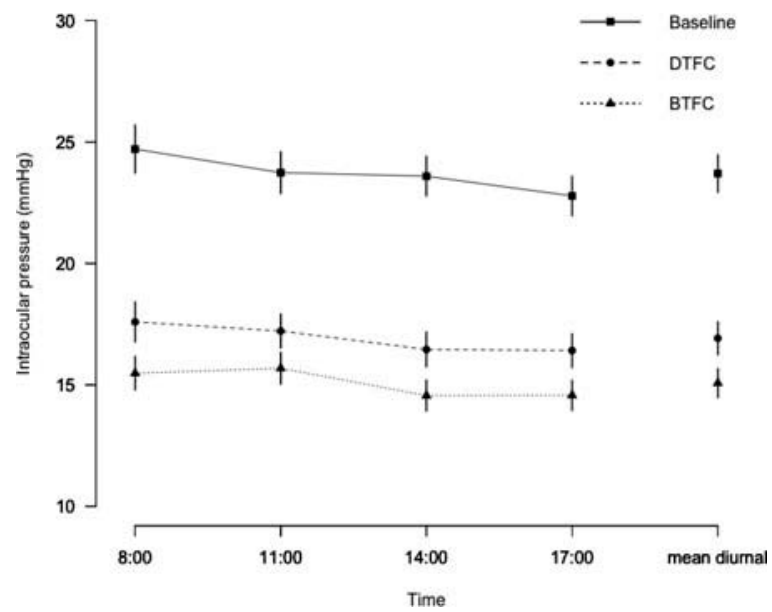

Figure 1. Mean intraocular pressure $\pm 95 \% \mathrm{Cl}$ at each individual time point and for the diurnal intraocular pressure for baseline, DTFC, and BTFC treatment groups.

The percentage IOP reduction from baseline was $28.1 \%$ for DTFC and $36 \%$ for BTFC $(p<0.0001)$.

The proportion of patients with a mean diurnal IOP of less than $18 \mathrm{mmHg}, 16 \mathrm{mmHg}$, and $14 \mathrm{mmHg}$ was $76 \%, 35.4 \%$, and $12.5 \%$ with DTFC and $81.2 \%, 68.8 \%$, and $37.5 \%$ with BTFC respectively $(p=0.20, p<0.01, p<0.0001)$.

The mean diurnal IOP fluctuation was $4.7 \pm 2.6 \mathrm{mmHg}$ (baseline), $3.3 \pm 1.5 \mathrm{mmHg}$ (with DTFC), and $3.0 \pm$ $1.6 \mathrm{mmHg}$ after therapy was switched to BTFC $(p<$ 0.0001 from baseline and each treatment; $p=0.17$ for DTFC compared to BTFC).

\section{Safety and tolerability}

Medical records reported severe conjunctival hyperemia in $2 \%$ (DTFC) and in $4.1 \%$ (BTFC), mild conjunctival hyperemia in $8.3 \%$ (DTFC) and in $14.5 \%$ (BTFC), moderate keratitis in $3.1 \%$ (DTFC) and $2 \%$ (BTFC), mild keratitis in $6.2 \%$ (DTFC) and $3.1 \%$ (BTFC) of patients. No severe adverse events related to the therapy were reported for either of the treatments at any time point.

\section{Discussion}

In this study, we retrospectively compared the diurnal IOP lowering efficacy of DTFC and BTFC. Patients treated with DTFC with poor IOP control (as judged by their treating physician) or complaining of ocular discomfort were switched to BTFC. Although both medications are fixed combinations of two drugs, BTFC offers the advantage of a once-daily therapy compared to the twice-daily therapy of DTFC. The simplified regimen of a once-daily treatment has been proven to impact positively on patient adherence to therapy and on quality of life. ${ }^{9} \quad$ Both medications significantly reduced IOP from untreated baseline levels. Analysis based on age, gender, and previous treatments revealed that variations of mean IOP were similar among strata.

The once-daily BTFC obtained a significantly lower mean diurnal IOP, and a significantly higher proportion of patients achieving an established target IOP when compared to DTFC.

The mean diurnal IOP difference between the two medications was $1.84 \mathrm{mmHg}$ in this study. This is likely to be clinically meaningful since a reduction of $1 \mathrm{mmHg}$ has been reported to decrease the risk of progression in glaucoma by between $10 \%$ and $19 \%$. $^{2,4}$

The $28.63 \%$ IOP reduction for DTFC and 36.39\% IOP reduction for BTFC compared to baseline is in agreement with the expected IOP lowering effect of these drugs as reported by Cheng and associates in their meta-analysis that found a $29.9 \%$ and $34.3 \%$ mean relative reduction from baseline for DTFC and BTFC respectively. ${ }^{12}$ The fixed combination of bimatoprost and timolol has been shown to have a similar IOP lowering efficacy to the unfixed combination of its two active ingredients $^{13}$ and a significantly superior efficacy compared with each of its active components. ${ }^{14}$ In exfoliative glaucoma, BTFC demonstrated better IOP control than bimatoprost $^{15}$ and than latanoprost monotherapy over 24 hours. ${ }^{16}$

In head-to-head studies BTFC was found to have a greater IOP lowering efficacy than latanoprost plus timolol $\mathrm{FC}^{17,18}$ and travoprost plus timolol FC. ${ }^{19,20}$ However, a recent prospective study compared the efficacy of BTFC with latanoprost plus timolol FC in patients switched from latanoprost monotherapy and this study showed no significant differences in mean IOP between the two fixed combinations. ${ }^{21}$ In addition, Schnober

Table 2. Comparison of diurnal IOP and diurnal IOP fluctuation at baseline, with DTFC and with BTFC $(n=96)$.

\begin{tabular}{|c|c|c|c|c|c|c|c|c|c|}
\hline & Baseline & DTFC & BTFC & DTFC - BTFC & & Baseline- DTFC & & Baseline- BTFC & \\
\hline Measurement & $\begin{array}{c}\text { Mean } \\
(95 \% \mathrm{Cl})\end{array}$ & $\begin{array}{c}\text { Mean } \\
(95 \% \mathrm{Cl})\end{array}$ & $\begin{array}{c}\text { Mean } \\
(95 \% \mathrm{CI})\end{array}$ & $\begin{array}{l}\text { Mean } \Delta \\
(95 \% \mathrm{Cl})\end{array}$ & $p$-value & $\begin{array}{l}\text { Mean } \Delta \\
(95 \% \mathrm{Cl})\end{array}$ & $p$-value & $\begin{array}{c}\text { Mean } \Delta \\
(95 \% \mathrm{Cl})\end{array}$ & $p$-value \\
\hline 08:00 & $24.7(23.7-25.7)$ & $17.6(16.8-18.4)$ & $15.5(14.8-16.2)$ & $2.1(1.5-2.8)$ & $<0.0001^{*}$ & $7.1(6.3-8.0)$ & $<0.0001^{*}$ & $9.2(8.3-10.1)$ & $<0.0001^{*}$ \\
\hline $11: 00$ & $23.7(22.9-24.6)$ & $17.2(16.5-17.9)$ & $15.7(15.0-16.3)$ & $1.5(0.9-2.2)$ & $<0.0001^{*}$ & $6.5(5.8-7.3)$ & $<0.0001^{*}$ & $8.1(7.2-8.9)$ & $<0.0001^{*}$ \\
\hline $14: 00$ & $23.6(22.8-24.4)$ & $16.5(15.7-17.2)$ & $14.6(13.9-15.2)$ & $1.9(1.3-2.5)$ & $<0.0001^{*}$ & $7.1(6.4-7.9)$ & $<0.0001^{*}$ & $9.0(8.3-9.8)$ & $<0.0001^{*}$ \\
\hline $17: 00$ & $22.8(22.0-23.6)$ & $16.4(15.7-17.1)$ & $14.6(13.9-15.2)$ & $1.8(1.1-2.6)$ & $<0.0001^{*}$ & $6.4(5.5-7.2)$ & $<0.0001^{*}$ & $8.2(7.5-9.0)$ & $<0.0001^{*}$ \\
\hline Mean diurnal IOP & $23.7(22.9-24.5)$ & $\begin{array}{l}16.9 \text { (16.2-17.6) } \\
(28.1 \%) \#\end{array}$ & $\begin{array}{l}15.1 \text { (14.5-15.7) } \\
(36.0 \%) \#\end{array}$ & $1.8(1.3-2.4)$ & $<0.0001$ & $6.8(6.1-7.5)$ & $<0.0001$ & $8.6(8.0-9.3)$ & $<0.0001$ \\
\hline Mean diurnal IOP fluctuation & $4.7(4.1-5.2)$ & $3.3(2.9-3.6)$ & $3.0(2.6-3.3)$ & $0.3(-0.1-0.7)$ & 0.1718 & $1.4(0.9-1.9)$ & $<0.0001$ & $1.7(1.2-2.2)$ & $<0.0001$ \\
\hline
\end{tabular}

*Bonferroni adjusted $p$-values.

\# Percentage reduction from baseline.

DTFC = dorzolamide-timolol fixed combination

BTFC $=$ bimatoprost-timolol fixed combination . 
and co-authors showed an additional IOP lowering effect when patients previously treated with BTFC were changed to travoprost plus timolol FC. ${ }^{22}$

Aptel and co-workers performed a meta-analysis of clinical trials comparing the different prostaglandin plus timolol FCs and they concluded that a greater IOP lowering efficacy was achieved with BTFC compared with either travoprost or latanoprost plus timolol FC. ${ }^{23}$

Few studies have compared prostaglandin plus timolol FC with carbonic anhydrase inhibitor plus timolol FC. ${ }^{10,24,25}$ In the study by Shin and associates, ${ }^{24} 253$ patients inadequately controlled by monotherapy were randomized to latanoprost plus timolol FC (LTFC) or DTFC. The study group consisted of both Caucasian subjects (63.7\%) and African-Americans (32.7\%). The authors found that the IOP lowering effect was slightly but statistically significantly greater with LTFC than with DTFC. In a Cyenkel and co-authors study, ${ }^{25}$ thirty-two Caucasian patients were randomized to DTFC or LTFC. Although the IOP was lower with the prostaglandin plus timolol FC compared to DTFC (19.5 $\mathrm{mmHg}$ with DTFC, and $18.9 \mathrm{mmHg}$ with LTFC) the difference was not statistically significant. The study by Jothi and associates is the only study to date comparing BTFC with DTFC. ${ }^{10}$ The authors found a superior IOP lowering efficacy in Indian patients randomized to BTFC compared to DTFC.

An important difference between the current paper and the work by Jothi et al. is in the design of the study as the former is a retrospective analysis whereas the latter was a randomized, prospective study. However, the current study has a larger sample size and the mean IOP was obtained in each patient by diurnal IOP curves as opposed to the single IOP measurement performed at each study visit in the study by Jothi et al. Despite these differences, the mean IOPs reported by Jothi et al. with each treatment $(15.45 \mathrm{mmHg}$ with BTFC and $17.25 \mathrm{mmHg}$ with DTFC) were similar to our findings. The percentage IOP reduction from baseline was superior in the Jothi et al. study $(45.77 \%$ with BTFC and $35.41 \%$ with DTFC) because the baseline IOPs were higher than in the current study. This difference may be partially explained by the "trial effect" as the Jothi et al. study was a randomized, prospective study. In addition, in the Jothi et al. study, patients were randomized into two groups according to their economic status and this could have biased the study in terms of patient adherence to therapy. Finally, our study population consisted of only Caucasian subjects, whereas that of Jothi and co-authors consisted of only Indian participants, therefore racial differences in terms of drug response need to be considered.

The PRESSURE study, ${ }^{26}$ a study comparing the prostaglandin efficacy in different racial groups, did not find any significant difference in terms of treatment effect between the 3 considered medications (latanoprost, travoprost and bimatoprost) or between the 2 ethnic groups (White or Other), and no interaction between race and drug was detected. However, the PRESSURE study did not evaluate prostaglandin plus timolol FC and DTFC, and the sample size was too small to conclusively exclude racial differences in drug response.

In this study, we also investigated IOP fluctuation and we found that both treatments significantly lowered IOP fluctuation compared to baseline. IOP fluctuation was lower with BTFC that with DTFC, but this difference was not found to be statistically significant. Although it has been suggested that IOP fluctuation may play a role in glaucoma progression, studies exploring this topic have reported mixed findings. In the Advanced Glaucoma Intervention Study ${ }^{3}$ and in the study by Hong et al., ${ }^{27} \mathrm{IOP}$ fluctuation was one of the predictive factors for glaucoma worsening. The Early Manifest Glaucoma Trial, ${ }^{2}$ however, failed to prove that IOP fluctuation is an independent risk factor for glaucoma progression.

The retrospective nature of this study does not allow an accurate evaluation of the safety of the respective drugs, however adverse events recorded in the medical charts were reported and analyzed. Conjunctival hyperemia is the most common drugrelated adverse event of prostaglandins. BTFC has been reported to be associated with a lower incidence of conjunctival hyperemia than an unfixed combination of bimatoprost and timolol ${ }^{13}$ or bimatoprost alone. ${ }^{14,15}$ These findings have been corroborated by two recent meta-analyses reporting that prostaglandin plus timolol FCs lead to a significantly lower incidence of ocular hyperemia than monotherapy with their respective prostaglandins. ${ }^{21,28}$

In our work, the overall proportion of patients with treatment related adverse event was $19.6 \%$ and $23.7 \%$ with DTFC and BTFC respectively.

In common with the paper by Maruyama et al. that compared BTFC with latanoprost plus timolol FC, ${ }^{21}$ we noted a slightly higher proportion of patients showing conjunctival hyperemia with BTFC (18.6\% vs $10.3 \%)$. A slightly higher proportion of patients showed superficial keratitis with DTFC (9.3\% vs 5.1\%).

These results suggest a similar safety and tolerability profile of the two FCs and are in agreement with the findings of Jothi et al. ${ }^{10}$

We recognize the limitations of this study. First, this study carries the attendant limitations of any retrospective analysis. Second, there was no washout period between treatments. To account for that, we only analyzed the IOP curves performed more than 12 weeks after the previous treatment was changed. During this period the effect of the drugs was likely to be completely washed out. ${ }^{29-32}$ Third, functional outcomes were not analyzed (it was not the aim of this study). Studies with functional end points and with a longer follow-up are warranted to elucidate the role of this difference in mean diurnal IOP on glaucoma progression. Finally, our study population was a relatively homogeneous group of Caucasian patients with moderate glaucoma switched from DTFC to BTFC, so the interpretation of our findings should be restricted to similar patients.

In conclusion, we found that DTFC and BTFC significantly reduced IOP compared to baseline. BTFC showed a greater IOP lowering efficacy compared to the previous treatment with DTFC in patients with open angle glaucoma. Our work suggests that patients with poorly controlled IOP with DTFC are likely to achieve a better IOP control when switched to BTFC.

\section{Declaration of interest}

The authors report no conflicts of interest. The authors alone are responsible for the content and writing of the paper.

\section{ORCID}

Susan E. Williams (D) http://orcid.org/0000-0002-4479-8638

Paolo Nucci (D) http://orcid.org/0000-0002-4036-703X 


\section{References}

1. Kass MA, Heuer DK, Higginbotham EJ, Johnson CA, Keltner JL, Miller JP et al. The ocular hypertension treatment study: a randomized trial determines that topical ocular hypotensive medication delays or prevents the onset of primary open-angle glaucoma. Arch Ophthalmol 2002;120:701-713.

2. Heijl A, Leske MC, Bengtsson B, Hyman L, Bengtsson B, Hussein M. Early manifest glaucoma trial group. Reduction of intraocular pressure and glaucoma progression: results from the early manifest glaucoma trial. Arch Ophthalmol 2002;120:1268-1279.

3. The AGIS Investigators. The Advanced Glaucoma Intervention Study (AGIS): 7. The relationship between control of intraocular pressure and visual field deterioration. Am J Ophthalmol 2000;130:429-440.

4. Chauhan BC, Mikelberg FS, Artes PH, Balazsi AG, LeBlanc RP, Lesk MR et al. Canadian glaucoma study group. Canadian glaucoma study: 3. Impact of risk factors and intraocular pressure reduction on the rates of visual field change. Arch Ophthalmol 2010;128:1249-1255.

5. Collaborative Normal-Tension Glaucoma Study Group. Comparison of glaucomatous progression between untreated patients with normal- tension glaucoma and patients with therapeutically reduced intraocular pressures. Am J Ophthalmol 1998;126:487-497.

6. European Glaucoma Society (EGS). Terminology and Guidelines for Glaucoma (4th ed.). Savona, Italy: Editore Publi Comm; 2014. pp. 1-191.

7. Robin AL, Covert D. Does adjunctive glaucoma therapy affect adherence to the initial primary therapy? Ophthalmology 2005;112:863-868.

8. Konstas AG, Mikropoulos D, Stewart WC. Fixed combination therapy in glaucoma. In Shaarawy T, Hitchings R, Sherwood M, et al. (Eds). Chapter in "Glaucoma". New York, NY: Elsevier, 2009. pp. $565-575$.

9. Dunker S, Schmucker A, Maier H. Latanoprost/Timolol Fixed Combination Study Group. Tolerability, quality of life, and persistency of use in patients with glaucoma who are switched to the fixed combination of latanoprost and timolol. Adv Ther 2007;24:376-386.

10. Jothi R, Ismail AM, Senthamarai R, Pal S. A comparative study on the efficacy, safety, and cost-effectiveness of bimatoprost/timolol and dorzolamide/timololcombinations in glaucoma patients. Indian J Pharmacol 2010;42:362-365.

11. Ranno S, Sacchi M, Brancato C, Gilardi D, Lembo A, Nucci P. A prospective study evaluating IOP changes after switching from a therapy with prostaglandin eye drops containing preservatives to nonpreserved tafluprost in glaucoma patients. Sci World J 2012;2012:804730.

12. Cheng JW, Cheng SW, Gao LD, Lu GC, Wei RL. Intraocular pressure-lowering effects of commonly used fixed-combination drugs with timolol: a systematic review and meta-analysis. PLoS One 2012;7:e45079.

13. Hommer A. Ganfort investigators group I. A double-masked, randimized, parallel comparison of a fixed combination of bimatoprost $0.03 \% /$ timolol $0.5 \%$ with non-fi xed combination use in patients with glaucoma or ocular hypertension. Eur J Ophthalmol 2007;17:53-62.

14. Brandt JD, Cantor LB, Katz LJ, Batoosingh AL, Chou C, Bossowska I. Ganfort Investigators Group II. Bimatoprost/ timolol fixed combination: a 3-month double-masked, randomized parallel comparison to its individual components in patients with glaucoma or ocular hypertension. J Glaucoma 2008;17:211-216.

15. Konstas AG, Holló G, Mikropoulos D, Tsironi S, Haidich AB, Embeslidis $T$ et al. Twenty-four-hour intraocular pressure control with bimatoprost and the bimatoprost/timolol fixed combination administered in the morning, or evening in exfoliative glaucoma. $\mathrm{Br}$ J Ophthalmol 2010;94:209-213.

16. Konstas AG, Holló G, Mikropoulos DG, Haidich AB, Dimopoulos AT, Empeslidis T et al. 24-hour efficacy of the bimatoprosttimolol fixed combination versus latanoprost as first choice therapy in subjects with high-pressure exfoliation syndrome and glaucoma. Br J Ophthalmol 2013;97:857-861.

17. Martinez A, Sanchez M. Bimatoprost/timolol fixed combination vs latanoprost/timolol fixed combination in open-angle glaucoma patients. Eye 2009;23:810-818.

18. Centofanti M, Oddone F, Vetrugno M, Manni G, Fogagnolo P, Tanga $L$ et al. Efficacy of the fixed combinations of bimatoprost or latanoprost plus timolol in patients uncontrolled with prostaglandin monotherapy: a multicenter, randomized, investigator-masked, clinical study. Eur J Ophthalmol. 2009;19:66-71.

19. Centofanti M, Oddone F, Gandolfi S, Hommer A, Boehm A, Tanga L et al. Comparison of Travoprost and Bimatoprost plus timolol fixed combinations in open-angle glaucoma patients previously treated with latanoprost plus timolol fixed combination. Am J Ophthalmol. 2010;150:575-580.

20. Macky TA. Bimatoprost/Timolol versus Travoprost/Timolol fixed combinations in an egyptian population: a hospitalbased prospective randomized study. J Glaucoma 2014;23:561-566.

21. Maruyama Y, Ikeda Y, Mori K, Ueno M, Yoshikawa H, Kinoshita S. Comparison between bimatoprost and latanoprost-timolol fixed combination for efficacy and safety after switching patients from latanoprost. Clin Ophthalmol 2015;9:1429-1436.

22. Schnober D, Hubatsch DA, Scherzer ML. Efficacy and safety of fixed-combination travoprost $0.004 \% /$ timolol $0.5 \%$ in patients transitioning from bimatoprost $0.03 \% /$ timolol $0.5 \%$ combination therapy. Clin Ophthalmol 2015;9:825-832.

23. Aptel F, Cucherat M, Denis P. Efficacy and tolerability of prostaglandin-timolol fixed combinations: a meta-analysis of randomized clinical trials. Eur J Ophthalmol 2012;22:5-18.

24. Shin DH, Feldman RM, Sheu WP. Fixed combination latanoprost/ timolol study group. Efficacy and safety of the fixed combinations latanoprost/timolol versus dorzolamide/timolol in patients with elevated intraocular pressure. Ophthalmology 2004;111:276-282.

25. Cvenkel B, Stewart JA, Nelson LA, Stewart WC. Dorzolamide/ timolol fixed combination versus latanoprost/timolol fixed combination in patients with primary open-angle glaucoma or ocular hypertension. Curr Eye Res 2008;33:163-168.

26. Birt CM, Buys YM, Ahmed II, Trope GE. Toronto Area Glaucoma Society. Prostaglandin efficacy and safety study undertaken by race (the PRESSURE study). J Glaucoma 2010;19:460-467.

27. Hong S, Seong GJ, Hong YJ. Long-term intraocular pressure fluctuation and progressive visual field deterioration in patients with glaucoma and low intraocular pressures after a triple procedure. Arch Ophthalmol 2007;125:1010-1013.

28. Quaranta L, Biagioli E, Riva I, Rulli E, Poli D, Katsanos A et al. Prostaglandin analogs and timolol-fixed versus unfixed combinations or monotherapy for open-angle glaucoma: a systematic review and meta-analysis. J Ocul Pharmacol Ther 2013;29:382-389.

29. European Glaucoma Society (EGS). Terminology and Guidelines for Glaucoma. Editrice Dogma s.r.l. (3rd ed.). Savona, Italy; 2008. pp. 1-183.

30. Schlecht LP, Brubaker RF. The effects of withdrawal of timolol in chronically treated glaucoma patients. Ophthalmology 1988;95:1212-1216.

31. Hong YJ, Shin DH, Ahn BH, McCarty B. Intraocular pressure after a two-week washout following long-term timolol or levobunolol. J Ocul Pharmacol Ther 1995;11:107-112.

32. Stewart WC, Holmes KT, Johnson MA. Washout periods for brimonidine $0.2 \%$ and latanoprost $0.005 \%$. Am J Ophthalmol 2001;131:798-799. 